\title{
Correction to: The discovery of insulin in Toronto: beginning a 100 year journey of research and clinical achievement
}

\author{
Michael Fralick ${ }^{1,2,3} \cdot$ Bernard Zinman ${ }^{1,3}$ \\ Published online: 30 March 2021 \\ (C) Springer-Verlag GmbH Germany, part of Springer Nature 2021
}

\section{Correction to: Diabetologia}

https://doi.org/10.1007/s00125-020-05371-6

The authors wish to correct the text that stated Frederick Banting was born in London, Ontario (Canada); in fact he was born in Alliston, Ontario. Also, the text referred to Banting's unsuccessful application for a surgical internship, when in fact he applied for a surgical position at The Hospital for Sick Children in Toronto, Ontario. The corrected text reads as follows:

Banting was born in Alliston, Ontario and completed his medical school training at the University of Toronto. He intended to become a surgeon; however, his application for a surgical position at The Hospital for Sick Children, Toronto, was unsuccessful and he moved to London, Ontario, where he opened a general medicine practice.

Publisher's note Springer Nature remains neutral with regard to jurisdictional claims in published maps and institutional affiliations.

The online version of the original article can be found at https://doi.org/ 10.1007/s00125-020-05371-6

Michael Fralick

mike.fralick@mail.utoronto.ca

1 Sinai Health and the Department of Medicine, University of Toronto, Toronto, ON, Canada

2 Division of Internal Medicine, Faculty of Medicine, University of Toronto, Toronto, ON, Canada

3 Lunenfeld-Tanenbaum Research Institute, Mount Sinai Hospital, Toronto, ON, Canada 